mmol KCN. The effects depended on the crystal concentration, but the maximum stimulation approached $50 \%$ of that given by the soluble stimulus phorbol myristate acetate. The results could be plotted using the form of the Michaelis-Menten equation to give a $\mathrm{Km}$ for each crystal. For urate this was $12.5 \mathrm{mg}$ crystal $/ \mathrm{ml}$, for brushite $1.2 \mathrm{mg} / \mathrm{ml}$, for calcium hydroxyapatite $1.2 \mathrm{mg} / \mathrm{ml}$. Diamond and cholesterol crystals did not stimulate oxygen uptake.

Addition of brushite caused the production of superoxide and $\mathrm{H}_{2} \mathrm{O}_{2}$ by isolated neutrophils at concentrations similar to those found to stimulate oxygen uptake. Analysis of the temperature dependence of the stimulation of oxygen uptake showed that urate crystals were ineffective at temperatures below $23^{\circ} \mathrm{C}$; phorbol was effective at, and above, $-17 \cdot 5^{\circ} \mathrm{C}$. Urate and phorbol showed similar temperature dependence above this trigger temperature in Arrhenius plots.

Neither colchicine nor cytochalasin $B$ inhibited the crystal-induced burst of oxygen uptake over the usual concentration range at which these inhibitors are used. Inhibitors of SH-dependent enzymes and flavin analogues were, however, potent inhibitors.

This work was supported in part by grants from the Medical Research Council and from the Wellcome Trust. We are also grateful to Dr Paul Dieppe for his advice and co-operation.

\section{References}

1 Abramson S, Hoffstein S T, Weissman G. Superoxide anion generation by human neutrophil exposed to MSU: effect of protein adsorption and complement activation. Arthritis Rheum 1982; 25: 174-80.

2 Simchowitz L, Atkinson J P, Spilberg I. Stimulation of the respiratory burst in human neutrophils by crystal phagocytosis. Arthritis Rheum 1982; 25: 181-8.

3 Cross A R, Higson F K, Jones O T G, Harper A M, Segal A W. The enzymic reduction and kinetics of oxidation of cytochrome $b_{-245}$ of neutrophils. Biochem J 1982; 204: 479-85.

\title{
Crystal interactions with polymorphonuclear leucocytes studied by luminol-dependent chemiluminescence
}

\author{
PHILIP PLATT, MARCUS HUDDIE, AND W. CARSON DICK \\ From the Department of Rheumatology, University of Newcastle upon Tyne
}

In recent years the crystal arthropathies have emerged as a distinct group of diseases linked by common pathogenetic mechanisms. One topic thought to be important is the interaction between crystals and polymorphonuclear leucocytes in the production of inflammation. ${ }^{1}$ We describe a method that allows the study of early events in this interaction by means of luminol-dependent chemiluminescence.

Polymorphonuclear leucocytes were obtained from fresh normal peripheral blood by dextran sedimentation ${ }^{2}$ and suspended in phosphate buffered saline.

Luminol reacts with oxidising agents produced by the polymorph, ${ }^{3}$ in the form of superoxides, hydrogen peroxide, and hydroxyl radicals, to produce an unstable intermediate which spontaneously releases to a ground state releasing photons in the process. The reaction was followed on an LKB 1250 luminometer linked to a flat bed recorder. The reaction cell of the luminometer was thermostatically controlled and the reactants held at $37^{\circ} \mathrm{C}$. The reaction mixture consisted of $1 \mathrm{ml}$ of phosphate buffered saline medium containing $1.5 \times 10^{6}$ cells, $0 \cdot 1$ $\mathrm{ml}$ of a standard luminol solution, and $0 \cdot 1 \mathrm{ml}$ of a $1 \%$ crystal suspension.

A series of dose-response curves with varying concentrations in a fixed volume showed a linear response until concentrations greater than $3 \%$ were used. We have used this technique to investigate the ability of different crystal preparations to induce release of superoxides and other oxygen radicals from polymorphs. Of those crystals implicated in joint disease monosodium urate crystals produced the largest response, the responses of CPPD, hydroxyapatite, brushite and cholesterol being less than $20 \%$ of the response to MSU.

The inflammatory potential of crystals as measured by animal models and their surface charges have been shown to be highly correlated. ${ }^{4}$ We have demonstrated a high degree of correlation between the surface charge of MSU crystals as measured by electrophoretic mobility and the chemiluminescence response induced by the crystal preparations.

Luminol-dependent chemiluminescence appears to be a useful method for studying early events in the interaction of polymorphonuclear leucocyte membranes and crystal surfaces and may allow further clarification of factors initiating and modifying effector mechanisms of crystal induced disease.

\section{References}

1 Phelps P, McCarty D J. Crystal induced inflammation in canine joints II. The importance of polymorphonuclear leucocytes. Experimental Medicine 1966; 124: 115-26.

2 Boyum A. Isolation of leucocytes from human blood. Scand J Clin Lab Invest 1968; 21, suppl 97: 9-50.

3 Allen R C, Loose L D. Phagocytic activation of a luminol dependent chemiluminescence in rabbit alveolar and peritoneal macrophages. Biochim Biophys Acta 1981; 631: 380-5.

4 Dieppe P A, Swan A, Hornby J, Jenkins R, Luckman N P, Preece A W. Crystal surface charge and inflammation. Ann Rheum Dis 1980; 39: 606-11. 